\title{
Studies of the effect of a coal concentrator on NO formation in swirling coal combustion
}

\author{
Y. Zhang ${ }^{\mathrm{a}, *}$, L.X. Zhou ${ }^{\mathrm{b}}$, X.L. Wei ${ }^{\mathrm{a}}$, H.Z. Sheng ${ }^{\mathrm{a}}$ \\ ${ }^{a}$ Institute of Mechanics, Chinese Academy of Sciences, Beijing 100080, PR China \\ b The State Key Laboratory of Clean Coal Combustion, Tsinghua University, Beijing 100084, PR China
}

Received 13 August 2004; received in revised form 8 April 2005

Available online 1 September 2005

\begin{abstract}
To develop low-pollution burners, the effect of a coal concentrator on NO formation in swirling coal combustion is studied using both numerical simulation and experiments. The isothermal gas-particle two-phase velocities and particle concentration in a cold model of swirl burners with and without coal concentrators were measured using the phase Doppler particle anemometer (PDPA). A full two-fluid model of reacting gas-particle flows and coal combustion with an algebraic unified second-order moment (AUSM) turbulence-chemistry model for the turbulent reaction rate of NO formation are used to simulate swirling coal combustion and NO formation with different coal concentrators. The results give the turbulent kinetic energy, particle concentration, temperature and NO concentration in cases of with and without coal concentrators. The predicted results for cold two-phase flows are in good agreement with the PDPA measurement results, showing that the coal concentrator increases the turbulence and particle concentration in the recirculation zone. The combustion modeling results indicate that although the coal concentrator increases the turbulence and combustion temperature, but still can remarkably reduce the NO formation due to creating high coal concentration in the recirculation zone.
\end{abstract}

(C) 2005 Elsevier Ltd. All rights reserved.

Keywords: Coal combustion; Coal concentrator; NO formation

\section{Introduction}

Since swirl coal burners are widely used in the utility boilers of power stations in China, it is important to develop low-pollutant swirl burners. Most of studies on reducing pollutant formation are focused on chemical methods. However, how to use the aerodynamic methods to reduce pollution still remains to be studied. It was found recently by both experiments and numerical

\footnotetext{
* Corresponding author. Tel.: +86 10625455333052

E-mail address: yuzhang@imech.ac.cn (Y. Zhang).
}

simulation that as the swirl increases; the NO formation at first decreases and then increases. There is an optimal swirl number for the lowest NO formation [1,2]. However, the swirl number affects not only NO formation, but also flame stabilization and burnout rate. It cannot be determined only by the lowest NO formation. Therefore, it is necessary to find other aerodynamic methods to change the inlet turbulence and fuel-air mixing. One possible approach is using the coal concentrator [3], but the effect of the concentrator on NO formation has not yet been systematically studied. In this paper, the effect of a coal concentrator on two-phase velocities, turbulent kinetic energy and particle concentration in a 
cold model of swirl burner are measured using a phaseDoppler particle anemometer (PDPA). The NO formation in swirling coal combustion is studied by numerical simulation. An algebraic unified second-order moment (AUSM) turbulence-chemistry model and a simplified Solomon model of $\mathrm{HCN}$ release for NO formation [4] are incorporated into a comprehensive full two-fluid model of reacting gas-particle flows and coal combustion [5]. The effect of a coal concentrator on NO formation is studied.

\section{Isothermal experimental set-up and measurement method}

The mean diameter of test particles is $45 \mu \mathrm{m}$. The particles with diameters less than $10 \mu \mathrm{m}$ are considered as tracer particles of the gas phase. The measurement system is a DANTEC 3-D PAPA. Fig. 1 shows the test section. Fig. 2 shows three cases: Case $1-$ a cone-shaped concentrator is placed in the central tube; Case 2-a blocking is placed in the annular space; the primaryair with pulverized coal is supplied from the central tube; Case 3-no blocking and no concentrator. The geometrical sizes and inlet-flow parameters are given in Tables 1 and 2 .

\section{The AUSM turbulence chemistry model}

Neglecting the third-order correlation, the time-averaged reaction rate in turbulent flows is

$\bar{W}_{\mathrm{s}}=B \rho^{2}\left[\left(\overline{Y_{1} Y_{2}}+\overline{Y_{1}^{\prime} Y_{2}^{\prime}}\right) \bar{K}+\overline{Y_{1}} \overline{K^{\prime} Y_{2}^{\prime}}+\overline{Y_{2}} \overline{K^{\prime} Y_{1}^{\prime}}\right]$,

where $\bar{K}=\int \exp (-E / R T) p(T) \mathrm{d} T, p(T)$ is the PDF of temperature. Assuming a simplest top-hat PDF gives

$\bar{K}=\left\{\exp \left[-E / R\left(T+g_{T}^{1 / 2}\right)\right]+\exp \left[-E / R\left(T-g_{T}^{1 / 2}\right)\right]\right\} / 2$.
Other forms of presumed PDF, such as $\beta$ PDF or Gaussian PDF can be used, but there is only slight difference in the final results. The correlations in Eq. (1) are closed using the following algebraic expressions:

$\overline{Y_{1}^{\prime} Y_{2}^{\prime}}=C_{1} \frac{k^{3}}{\varepsilon^{2}} \frac{\partial \overline{Y_{1}}}{\partial x_{j}} \frac{\partial \overline{Y_{2}}}{\partial x_{j}}$,
$\overline{K^{\prime} Y_{1}^{\prime}}=C_{2} \frac{k^{3}}{\varepsilon^{2}} \frac{\partial \bar{K}}{\partial x_{j}} \frac{\partial \overline{Y_{1}}}{\partial x_{j}}$,
$\overline{K^{\prime} Y_{2}^{\prime}}=C_{3} \frac{k^{3}}{\varepsilon^{2}} \frac{\partial \bar{K}}{\partial x_{j}} \frac{\partial \overline{Y_{2}}}{\partial x_{j}}$,

where $k, \varepsilon$ are the turbulent kinetic energy and its dissipation rate. The temperature or enthalpy fluctuation correlation $g_{T}$ can be determined by

$$
\begin{aligned}
& \frac{\partial}{\partial x}\left(\rho u \overline{h^{\prime 2}}\right)+\frac{\partial}{r \partial r}\left(r \rho v \overline{h^{\prime 2}}\right)+\frac{\partial}{r \partial \theta}\left(\rho w \overline{h^{\prime 2}}\right) \\
& =\frac{\partial}{\partial x}\left(\lambda_{t} \frac{\partial h^{\prime 2}}{\partial x}\right)+\frac{\partial}{r \partial r}\left(r \lambda_{t} \frac{\partial h^{\prime 2}}{\partial r}\right)+\frac{\partial}{r^{2} \partial \theta}\left(\lambda_{t} \frac{\partial \bar{h}}{\partial \theta}\right) \\
& \quad+c_{1} \mu_{t}\left[\left(\frac{\partial \bar{h}}{\partial x}\right)^{2}+\left(\frac{\partial \bar{h}}{\partial r}\right)^{2}+\frac{1}{r^{2}}\left(\frac{\partial \bar{h}}{\partial \theta}\right)\right]+c_{2} \frac{\varepsilon}{\kappa} \rho \overline{h^{\prime 2}},
\end{aligned}
$$

where $h$ is the thermal enthalpy of gas, which is determined by

$h=\left(c_{p 0}+0.106 \times T\right) \times T$.

Eqs. (1)-(4) constitute the algebraic unified secondorder moment (AUSM) turbulence-chemistry model. For the reaction kinetics of thermal NO formation, the well-known Zeldovich mechanism is used [6]. For the reaction kinetics of fuel NO formation, the De Soete mechanism is used [7].

\section{The full two-fluid model for reaction gas-particle flows and coal combustion}

For the comprehensive modeling of reacting gas-particle flows and coal combustion, a full two-fluid model [5] is used, that is, the continuity, momentum, energy

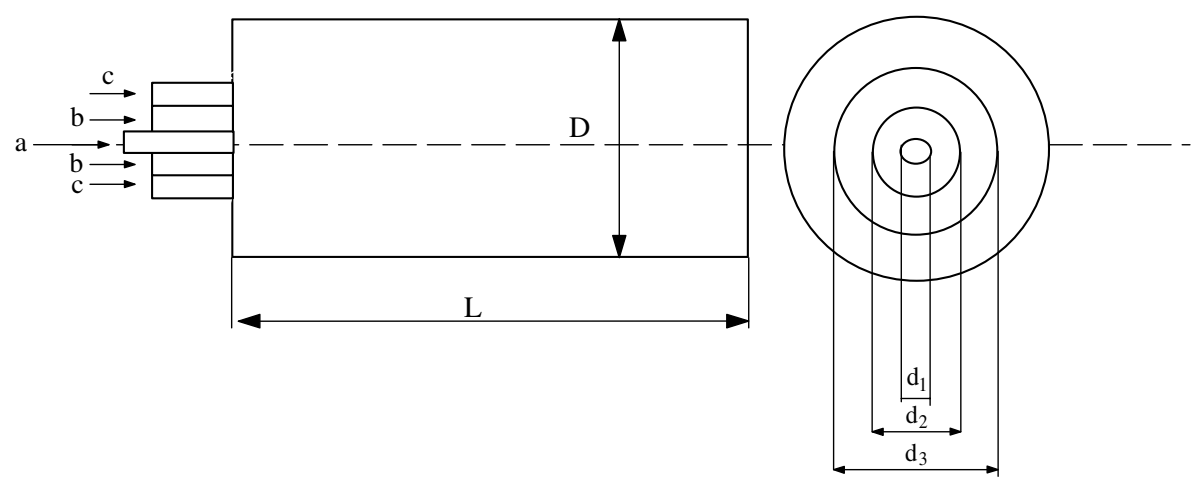

Fig. 1. PDPA optical units' arrangement. 

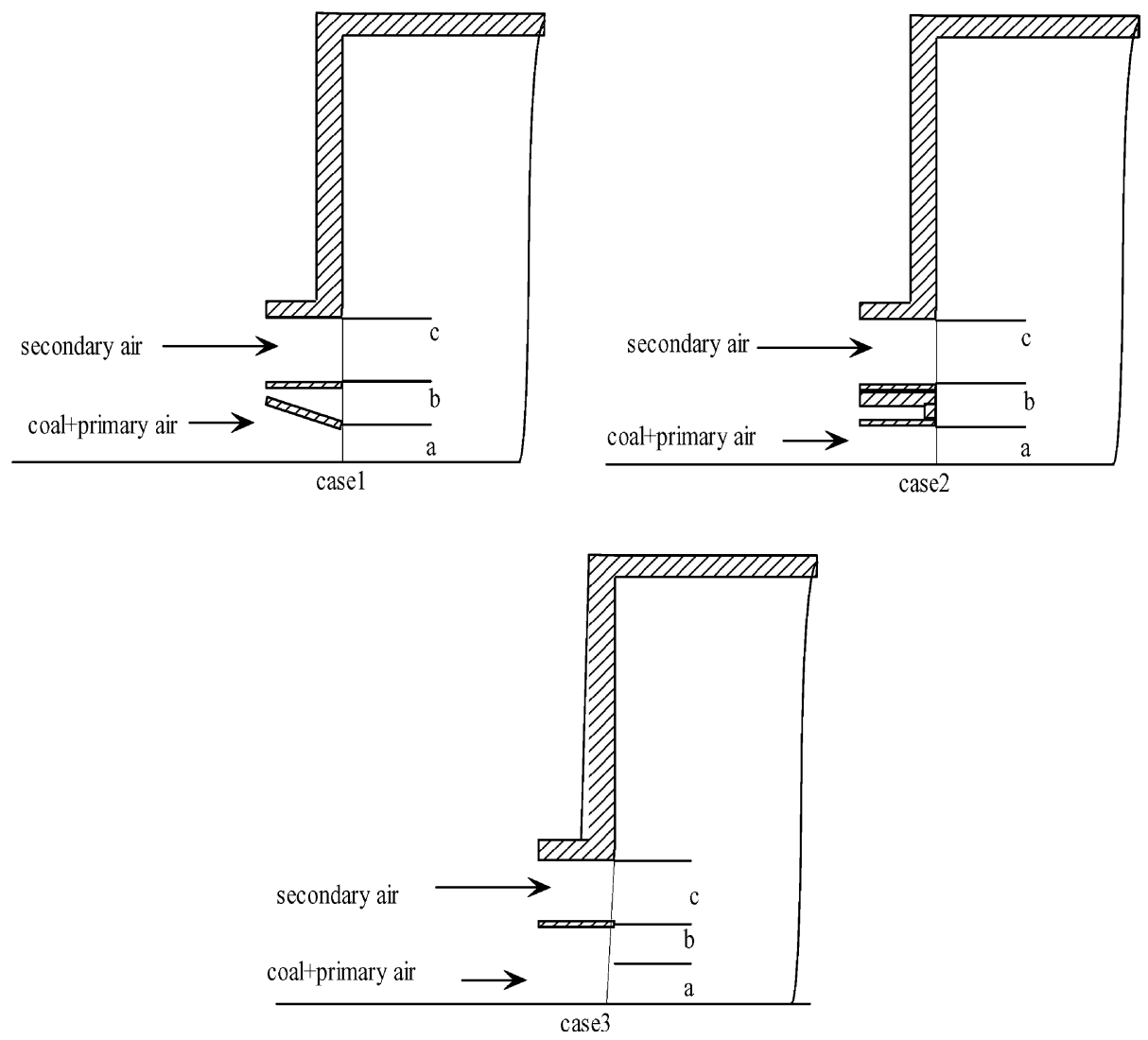

Fig. 2. Three cases.

Table 1

Geometrical sizes

\begin{tabular}{lllll}
\hline$D$ & $L$ & $d_{1}$ & $d_{2}$ & $d_{3}$ \\
\hline $0.15 \mathrm{~m}$ & $1.0 \mathrm{~m}$ & $0.011 \mathrm{~m}$ & $0.026 \mathrm{~m}$ & $0.056 \mathrm{~m}$ \\
\hline
\end{tabular}

Table 2

Inlet-flow parameters

\begin{tabular}{llll}
\hline & $\begin{array}{l}\text { Air flow } \\
\text { rate }(\mathrm{kg} / \mathrm{h})\end{array}$ & $\begin{array}{l}\text { Coal feeding } \\
\text { rate }(\mathrm{kg} / \mathrm{h})\end{array}$ & $\begin{array}{l}\text { Swirl } \\
\text { number }\end{array}$ \\
\hline Primary air & 21.77 & 12.77 & 0.0
\end{tabular}

and turbulent kinetic energy equations for both gas and particle phases are derived and solved in Eulerian coordinates.

\section{Result and discussion}

For the simulation of isothermal gas-particle flows, the geometrical configuration, the sizes of the combustor, a well as the inlet-flow parameters are the same as those given in experiments. Figs. 3 and 4 show the measured and predicted turbulent kinetic energy for Cases 1 and 3 . The prediction results are reasonable, compared with experimental results. Both measurements and simulation results indicate that in the near-axis region the turbulent kinetic energy for Case 1 is higher than what of Case 3. Clearly, the coal concentrator increases the turbulent kinetic energy. Fig. 5 shows the measured and predicted particle concentration for three cases at the cross-section of $x=0.265$. For measurement results, it is well known that PDPA can give only qualitative results of particle concentration distribution. Even so, both experimental results and predictions indicate that the coal concentrator increases the particle concentration in the near-axis region. The particle concentration in the near-axis region for Case 2 is the highest and that for Case 3 is lowest.

For coal combustion and NO formation modeling, the geometrical configuration and the arrangement of the blocking and coal concentrator are the same as those in cold model experiments. Fig. 6 gives the temperature distribution for Case 1 and Case 3. The temperature for Case 1 is higher than that for Case 3. It implies that the coal concentrator increases the combustion temperature in main combustion zone. Fig. 7 shows the NO concentration distribution for Case 1 and Case 3. The 


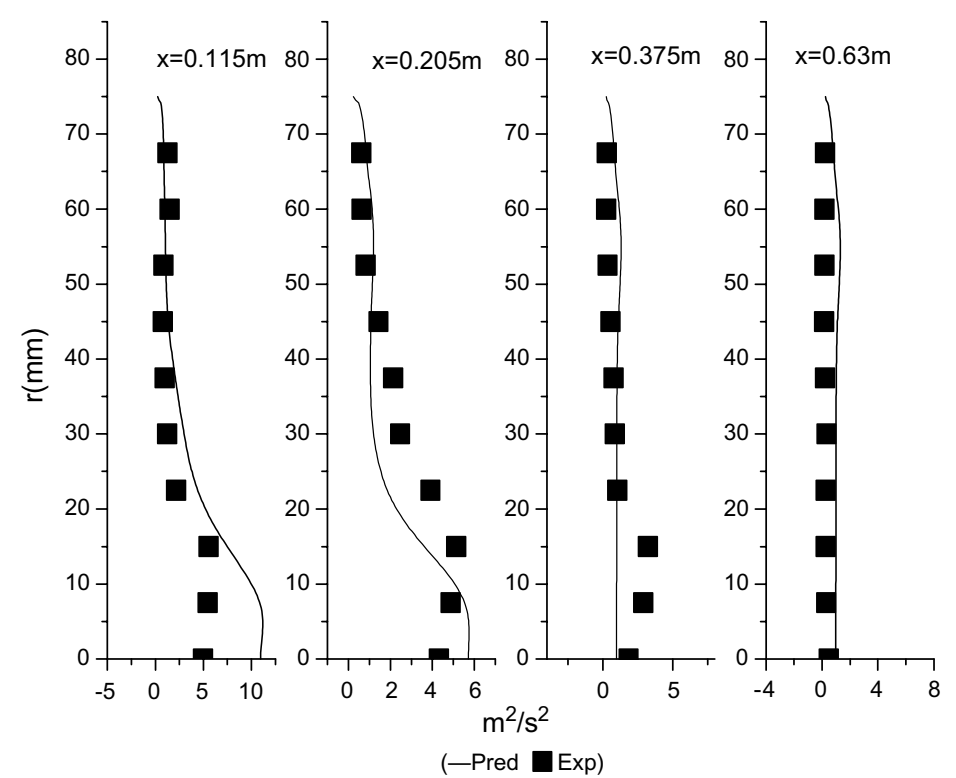

Fig. 3. Turbulent kinetic energy (Case 1).

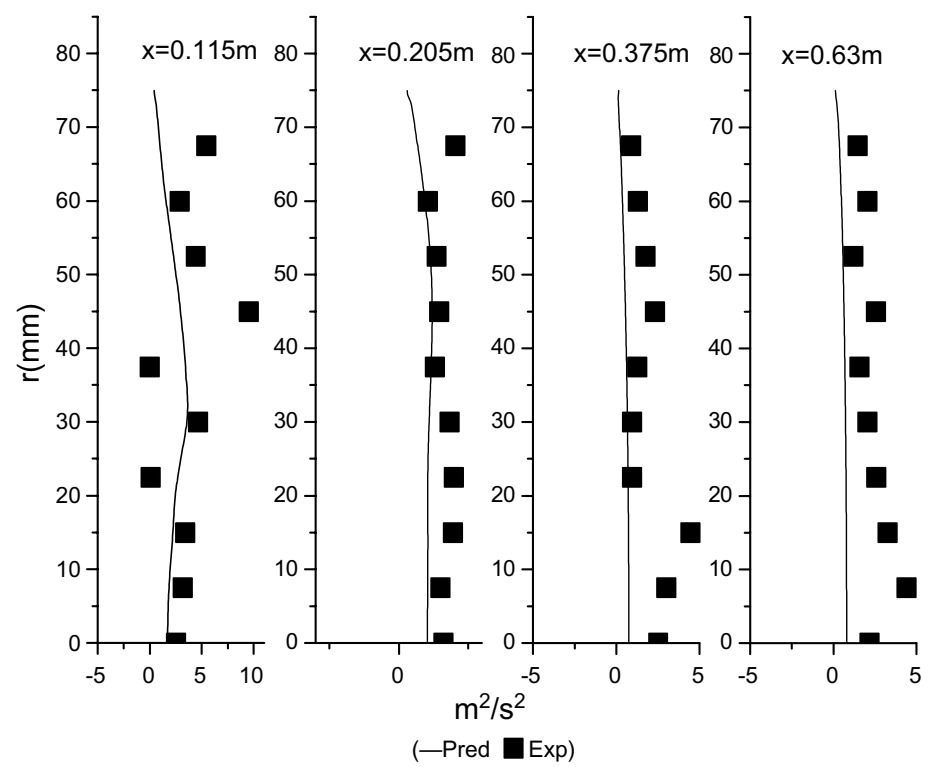

Fig. 4. Turbulent kinetic energy (Case 3).

NO concentration for Case 1 is much lower than that for Case 3. The Case 1's NO emission is nearly 600 ppm while the Case 3's NO emission is almost 700 ppm. Clearly, the coal concentrator reduces NO formation. The reason is that although the coal concentrator increases the turbulence intensity and combustion temperature, but it significantly increases the coal concentration in the inlet region to form the oxygen-lean combustion; hence the total effect is remarkably reducing the NO formation.

\section{Conclusions}

(1) The coal concentrator intensifies the gas turbulence and coal combustion in the inlet region.

(2) The coal concentrator creates higher coal concentration in the inlet region.

The global effect is that the coal concentrator remarkably reduces the NO formation. 

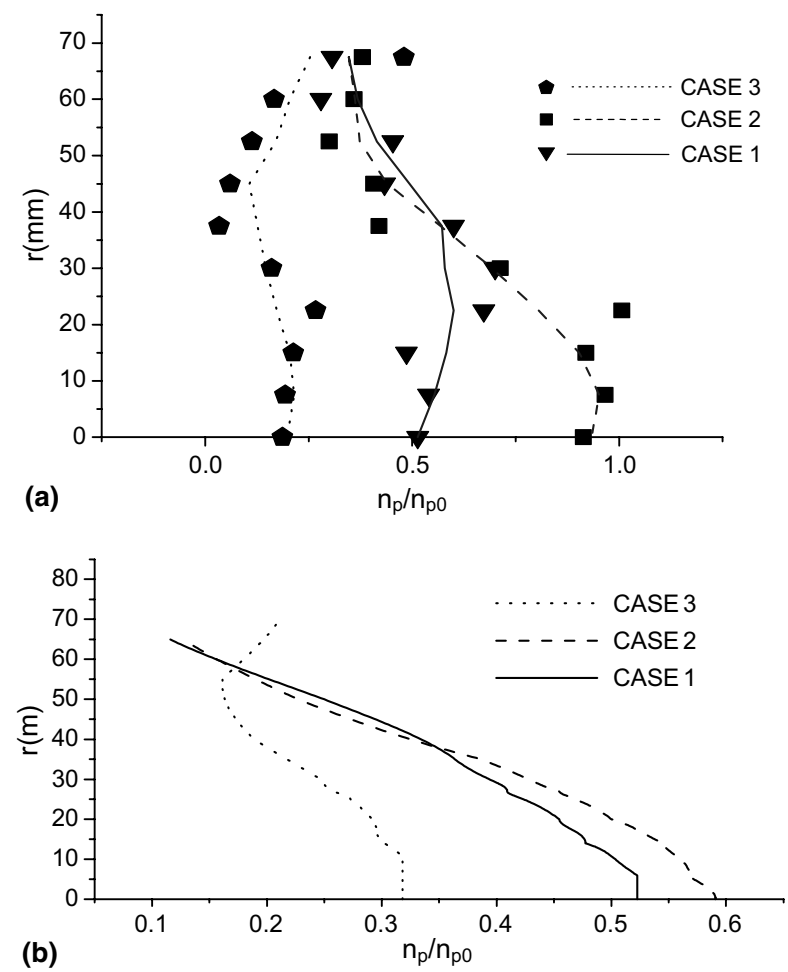

Fig. 5. Particle concentration ( $x=0.265 \mathrm{~m}$, a-measurements, $\mathrm{b}$-predictions).

(a)

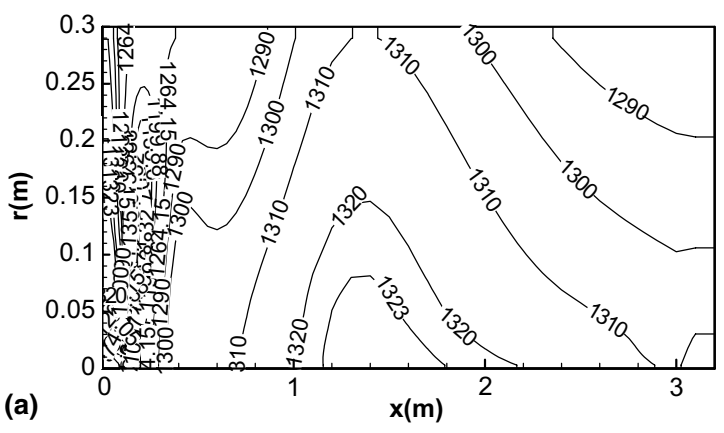

(b)

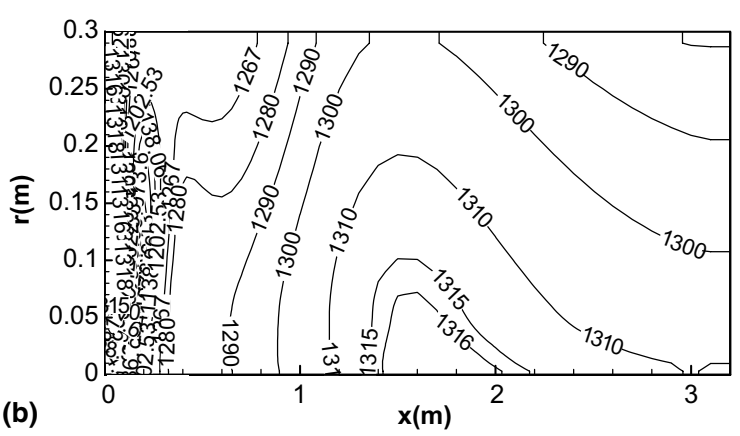

Fig. 6. Temperature (K, a-Case 1, b-Case 3).
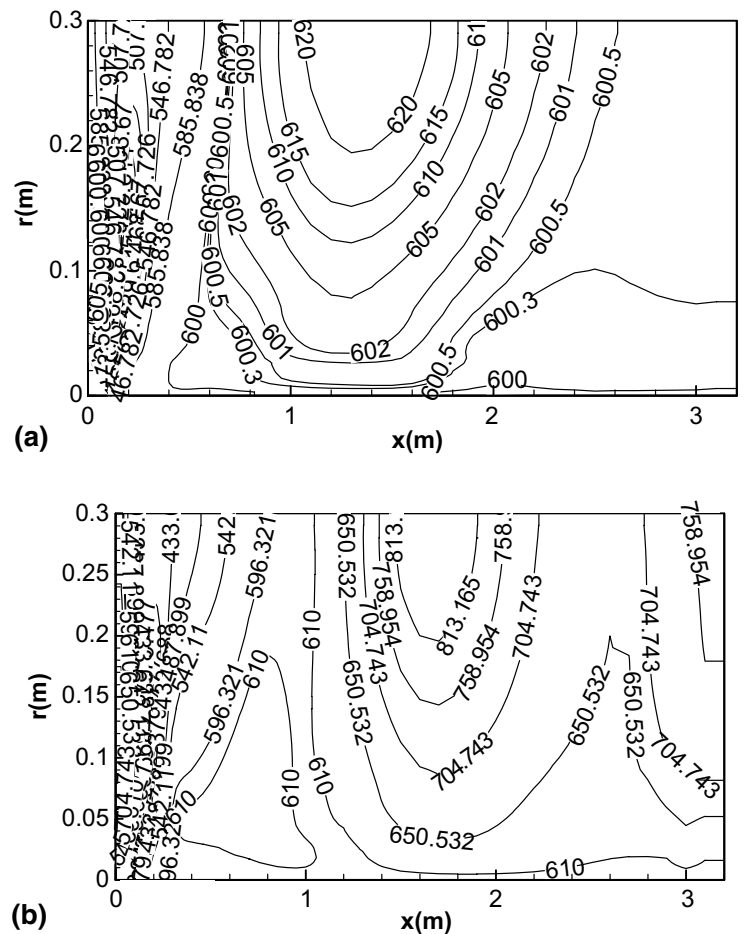

Fig. 7. NO concentration (ppm, a-Case 1, b-Case 3). 


\section{Acknowledgement}

Financial Support by the Chinese Special Funds for Major State Basic Research Projects (G1999022102) and National Natural Science Foundation of China (No. 50376068) is acknowledged.

\section{References}

[1] T. Abbas, P. Costen, M.A. Hassan, Combust. Sci. Technol. 93 (1993) 73-90.

[2] Y. Zhang, L.X. Zhou, J. Zhang, J. Eng. Thermophys. 24 (2003) 165-168 (in Chinese).
[3] Z.Q. Jin, J.D. Lu, S.Z. Wang, in: Proceedings of the International Conference on Energy Conversion and Application, Hangzhou, 2001, pp. 837-840.

[4] Y. Zhang, L.X. Zhou, J. Zhang, in: Proceedings of Symposium on Combustion, Chinese Society of Engineering Thermophysics, Beijing, 2002, pp. 151-156.

[5] L.X. Zhou, Y.C. Guo, W.Y. Lin, Combustion Science and Technology 150 (2000) 161-180.

[6] A. Okasanen, E. Maki-Mantila, in: Proc. 3rd Int. Conf. Comb. Tech. Clean Environ., Lisbon, 1995, Paper 183.

[7] G.G. De Soete, in: Twenty-third Symposium (international) on Combustion, The Combustion Institute, Pittsburgh, 1991, pp. 1257-1264. 